\title{
APPLICATION OF A LINE AMPACITY MODEL AND ITS USE IN TRANSMISSION LINES OPERATIONS
}

\author{
Jaroslav Šnajdr — Jan Sedláček — Zdeněk Vostracký *
}

\begin{abstract}
A conductor thermal model related to CIGRE and IEEE solutions was developed and compared with measurements. Two pylons of a single line were equipped with weather monitoring stations and conductor temperature sensors based on Surface Acoustic Wave (SAW) principle. Also a fiber optic distributed temperature sensing system was installed to provide additional data. Over 2.5 million data points were evaluated. Developed model deviation for more than $99 \%$ of values proved to be $\pm 1{ }^{\circ} \mathrm{C}$ for SAW sensor and $\pm 3.5^{\circ} \mathrm{C}$ for the fiber optic measurement. Several ampacity determination methods were described from a transmission grid operator's point of view. Their features were compared in order to show at which planning period they could be useful. A new method for dynamic line rating determination was proposed. Although it reduces maximum ampacity gain, its advantage lies in minimizing measurement systems while retaining relatively stable value and low risk of temperature limit exceeding.
\end{abstract}

K e y w or d s: ampacity, dynamic line rating, transmission line, heat transfer, conductor temperature measurement

\section{Nomenclature}

ACSR aluminium conductor steel reinforced

DLR dynamic line rating

SAW surface acoustic wave

$A_{A l} \quad$ total aluminium cross-section

$A_{F e}$ total steel cross-section

$b \quad$ temperature coefficient

$c_{A l} \quad$ specific heat capacity of conductor sheath

$c_{c} \quad$ conductor heat capacity

$c_{\mathrm{Fe}} \quad$ specific heat capacity of conductor core

$D \quad$ conductor diameter

$h_{c} \quad$ heat transfer coefficient

$I_{e f} \quad$ effective current

$I_{\max }$ ampacity

$I_{s} \quad$ intensity of solar radiation

$k_{A C} \quad$ AC resistance coefficient

$m_{c} \quad$ conductor mass

$P_{c} \quad$ corona losses

$P_{J} \quad$ Joule losses

$P_{k} \quad$ convective cooling

$P_{r} \quad$ radiative cooling

$P_{s} \quad$ solar heating

$P_{w} \quad$ evaporative cooling

$R_{D C}$ conductor DC resistance

$S \quad$ conductor surface

$s_{\text {land }}$ landscape sector for radiative cooling

$s_{s k y} \quad$ sky sector for radiative cooling

$t \quad$ time

$T_{c} \quad$ conductor temperature

$T_{\text {land }}$ landscape temperature

$T_{a m b}$ ambient temperature

$T_{\text {sky }} \quad$ sky temperature

$\varepsilon_{a} \quad$ absorptivity

$\varepsilon_{e} \quad$ conductor emissivity

$\rho_{A l} \quad$ conductor sheath material density

$\rho_{F e} \quad$ conductor core material density

$\sigma \quad$ Stephan-Boltzmann constant

\section{INTRODUCTION}

Computing and measuring capabilities of conductor temperature brought new ways of increasing current rating. Besides traditional solutions based on overhead lines hardware change or modification, new methods $[1,2]$ comprise actual ambient and conductor parameters. They are called Operation-based Methods and allow dynamically enhance conductor current carrying capacity. Ampere capacity - ampacity - has been simply stated by standards as nominal current at given constant weather conditions. It is derived from conductor maximum allowable temperature or its minimal clearance above ground.

A distinction among ampacity determination methods should be made in order to ensure conductors current carrying capacity under different conditions. Most commonly the ampacity of overhead conductors is given by national standards guaranteeing stable and safe values. Further differentiation in time leads to a statistical ampacity, which can provide loading plans in long-term periods. Actual weather ampacity of a conductor can be determined by measuring or predicting weather conditions along a line. To complete the list it is necessary to mention a possibility of conductor overloading for a limited time utilizing its thermal capacity. Deterministic ampacity models published in $[3,4]$ or non-physical solutions $[5,6]$ involve all of the main weather parameters.

The new goal was to develop a suitable thermal model of an overhead conductor for a single transmission line and to compare it with measurements. Two hotspots on the line had been chosen in accordance with the expected minimal wind flow. Measured weather data were consequently analyzed to reveal ampacity potential. Based on the experience of common dynamic line rating trends, a method suitable for application by operators was developed. The new proposed method offers determination of dynamic line rating based on using minimum number of

* Faculty of Electrical Engineering of the University of West Bohemia, Univerzitní 8, 30614, Pilsen, Czech Republic, jsnajdr@kee.zcu.cz, sedlacek@kee.zcu.cz, zdenekv@kee.zcu.cz 
environment parameters. Therefore it minimizes the number of measuring equipment while the safety is ensured. This technology can be also implemented on power cables, but further factors, such as [7], are necessary to analyze.

\section{CONDUCTOR THERMAL MODEL}

Due to the pilot project, our theoretical model was tailored on the specific conductor 382-AL1/49-ST1A. Using approaches mainly from CIGRE [8] and IEEE [9], the model was verified and its constants calibrated according to the measurements. The thermal balance of the conductor can be modeled using lumped parameters [10] as follows

$$
P_{J}+P_{s}+P_{c}=m_{c} c_{c} \frac{\mathrm{d} T_{c}}{\mathrm{~d} t}+P_{r}+P_{k}+P_{w} .
$$

The equation lacks corona heating and water evaporative cooling coefficients. While overhead conductors are designed to suppress significant corona effects, water evaporation can lower the temperature in the order of degrees Celsius [11]. Also the effect of radial temperature distribution was neglected because of direct comparison between the model and measurements.

\subsection{Joule losses}

Heating of a conductor caused by electric current and electromagnetic interactions is described by the following equation

$$
P_{J}=R_{D C} k_{A C} I_{e f}^{2}\left[1+b\left(T_{c}-293.15\right)\right] .
$$

It makes use of ACSR conductor's DC resistance at $20{ }^{\circ} \mathrm{C}$ provided by a manufacturer and the fact, that most of the current flows through the sheath wires. Thus temperature coefficient can be considered just for aluminium. The most problematic part can be represented by proper evaluation of $\mathrm{AC}$ resistance as the conductor is composed of a number of wires stranded around each other. According to [8] it is recommended to use $k_{A C}=1.0123$ for three-layered ACSR conductors.

\subsection{Solar heating}

Heat gain from solar radiation is defined by (3). Received heat is determined by the conductor diameter and its surface. Newly installed conductors emissivity can be as low as 0.23 , while weathered surface after several years in service can rise to 0.95 ; in [12] it is recommended in the case of thermally rated conductor over $70-80{ }^{\circ} \mathrm{C}$ to use mean value of $0.5-0.6$.

$$
P_{s}=\varepsilon_{a} D I_{s} .
$$

\subsection{Heat capacity}

Capability of accumulating heat by a conductor is expressed by a combination of its mass and specific heat capacity. For ACSR we can use in advantage the formula (4) for steel core and aluminium sheath. Although heat capacity is also dependent on temperature, the range of its operating values causes a negligible change.

$$
m_{c} c_{c}=c_{A l} \rho_{A l} A_{A l}+c_{F e} \rho_{F e} A_{F e} .
$$

\subsection{Radiative cooling}

In the case of a conductor placed in the open we can assume its surrounding with infinite surface. The equation below describes such a case

$$
P_{r}=\varepsilon_{e} \sigma S\left(T_{c}^{4}-T_{a m b}^{4}\right)
$$

Emissivity changes through time. Le [13] proposed an empirical formula (6) for conductor emissivity and absorptivity determination. Variable $Y$ stands for the number of years the conductor has been energised. According to the Le's formula, $\varepsilon_{a}$ and $\varepsilon_{e}$ equal to 0.5 should be reached after a single year of operation. But in [12] it is noted that data from certain US western states indicates that $\varepsilon_{a}$ and $\varepsilon_{e}$ may stay as low as 0.6 even after 10 years of operation. Thus the emissivity value was chosen constant 0.5 and consequently verified by measurements to be acceptable.

$$
\varepsilon_{e}=0.23+\frac{0.7 Y}{1.22+Y}
$$

Ambient temperature for radiative cooling is more difficult to obtain. Surrounding can be divided into two sectors - the sky above with approx. one third to quarter of the whole sector and the rest formed by buildup area, forests and land. The main difference between ambient temperatures is the sky temperature varies between -40 and $+10{ }^{\circ} \mathrm{C}$, while the extreme can reach up to $-56{ }^{\circ} \mathrm{C}[14]$. Although the sky temperature is not measured, simulations using (7) and (8) have shown that the nominally loaded conductor temperature can drop more than $5{ }^{\circ} \mathrm{C}$ [15]. In connection with the neglected effect of water evaporation, it could explain negative errors between model and measurement.

$$
\begin{gathered}
T_{a m b}=\sqrt[4]{s_{s k y} T_{s k y}^{4}+s_{\text {land }} T_{\text {land }}^{4}}, \\
s_{\text {sky }}=1-s_{\text {land }}
\end{gathered}
$$

\subsection{Convective cooling}

To calculate dissipated heat via convection it is possible to use two general approaches - Computational Fluid Dynamics (CFD) and convection correlation. Comparison of both methods for current application is published in [16-18]. The latter method uses Newton's law of cooling (9) whose most problematic part is to determine the heat transfer coefficient $\left(h_{c}\right)$. For this purpose correlation formulas were taken from [19]. By incorporating temperature dependent air parameters the final range of $h_{c}$ is depicted in Fig. 1.

$$
P_{c}=h_{c} S\left(T_{c}-T_{a m b}\right) .
$$




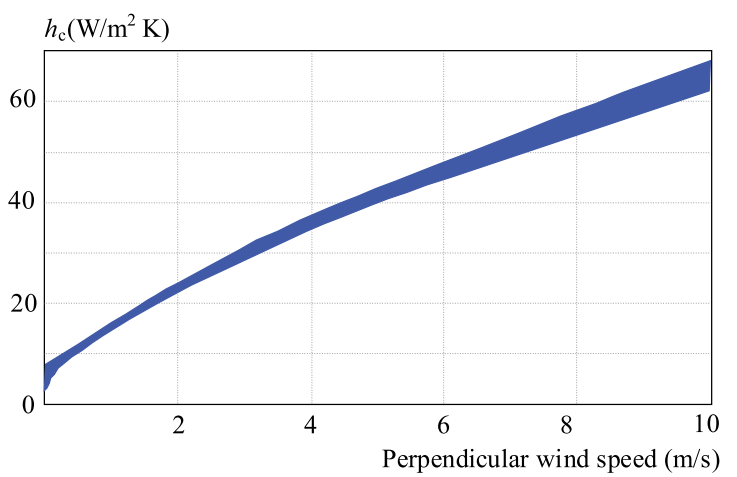

Fig. 1. Calculated heat transfer coefficient for modeled conductor

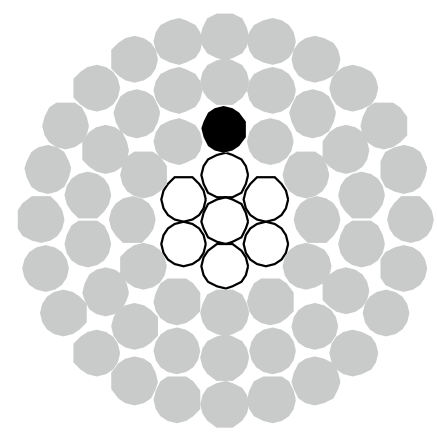

Fig. 2. An optical fiber (black) inside the modeled ACSR conductor (white - steel core. grev - aluminium) 「20〕

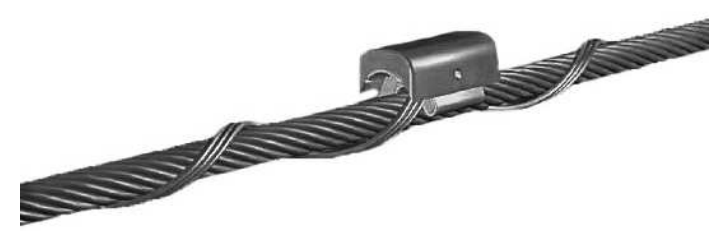

Fig. 3. SAW sensor placed on the conductor [21]

\section{MEASURED DATA}

Measurements were provided by the local transmission line operator in the Czech Republic, ČEPS, a.s. since April 2010. A weather station and RIBE Ritherm system (SAW technology) for local surface conductor temperature measurement were installed on each of two pylons along a single line. Also one conductor contained an optical fiber inside to compare its temperature using VALCAP system. Input values are ambient temperature $T_{a m b}$, conductor temperature $T_{c}$, total solar radiation intensity $I_{s}$, wind velocity $v$ and wind angle $\phi$. The data are available in the form of irregular sampling of pairs (time stamp, value), where each variable is sampled independently with different average sampling rate.

\section{COMPARISON OF THE THEORETICAL MODEL AND MEASUREMENTS}

Conductor temperature was modeled numerically applying adaptive Runge-Kutta-Fehlberg on formula (1).
Because of the way of the weather data reading, all of the values had to be interpolated. Results were compared with measured data from April 1st 2010 to April 30th 2013 to evaluate three year period. Typical temperature curve can be seen in Figs. 4 and 5. Each of the peaks represents daytime when sun radiation and current load considerably heat up the conductor.

As the dynamic ampacity determination should be used primarily for maximizing transmission capacity, it is necessary to compare model at highest current loads possible before putting the DLR technology into live operation. Since start of data acquisition typical line loading has been around $50 \%$ of nominal value with peak level of $90 \%$.

An evaluation of the long-term accuracy between models and temperature measurements was made using a boxplot. Figure 6 depicts such a comparison when $T_{c}$ modeled is subtracted from $T_{c}$ measured. It is obvious that the modeled temperature curve is more similar to the surface than the inner measurement. Half of the values is located within the range of $\pm 0.5{ }^{\circ} \mathrm{C}$ in the case of conductor surface measurement and $\pm 1{ }^{\circ} \mathrm{C}$ for inner temperature. The whiskers range is set according to the Matlab default value - the lowest datum still within 1.5 interquartile range of the lower quartile, and the highest datum still within 1.5 interquartile range of the upper quartile. The biggest error was calculated to be +13 and $-33{ }^{\circ} \mathrm{C}$, but it is important to note here, that these difference could be caused by faulty measurements, as it was difficult to distinguish them.

\section{APPLICATION OF THE MODEL FOR DIFFERENT TYPES OF AMPACITY}

Based on the model mentioned in Chapter 2, several types of ampacity were described and their advantages and disadvantages compared with each other. Actual steady-state ampacity can be determined by the following formula.

$$
I_{\max }=\sqrt{\frac{P_{k}+P_{r}-P_{s}}{R_{A C}}} .
$$

The term "ampacity" has generally a quite broad meaning. It stands for the maximum current load of a conductor in amperes (amperes capacity). The loading ampacity - can be categorized due to the fact it depends on several factors, such as ambient conditions and the dynamical characteristics of conductors. Therefore, it is appropriate to specify a qualifying adjective to the term ampacity. From this perspective it is possible to define five types of ampacity:

1) Standardized ampacity - static value derived from the worst-case combination of weather parameters,

2) Statistical ampacity - based on statistical evaluation of weather measurements; suitable for long-term (weeks, months) operation planning, 


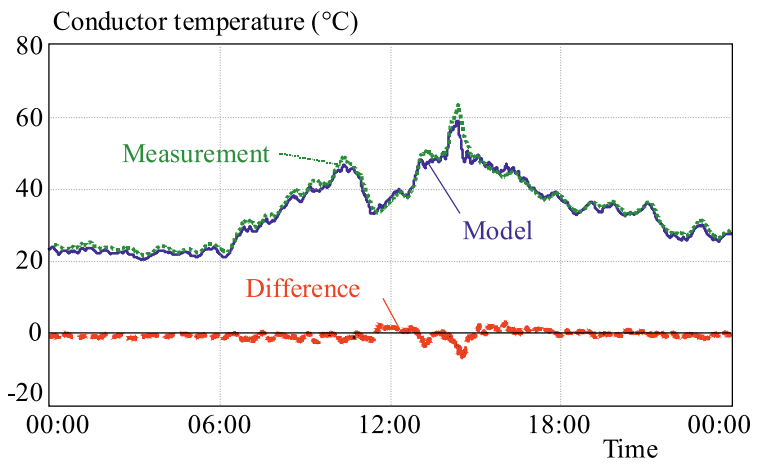

Fig. 4. Typical difference between modeled and measured conductor surface temperature

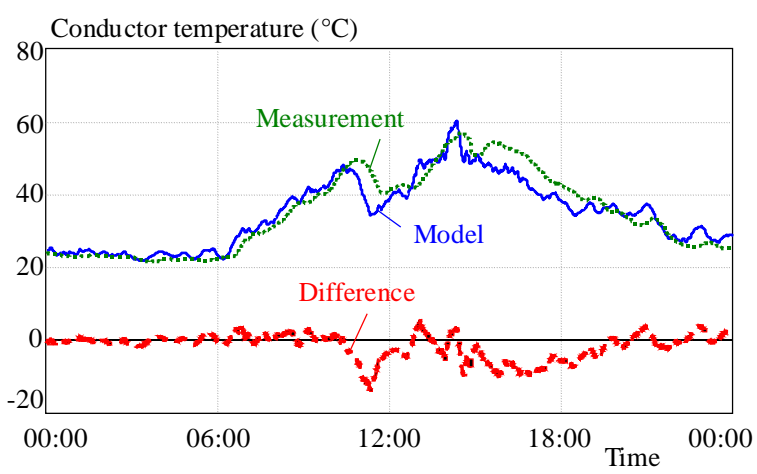

Fig. 5. Typical difference between modeled and measured conductor inner temperature

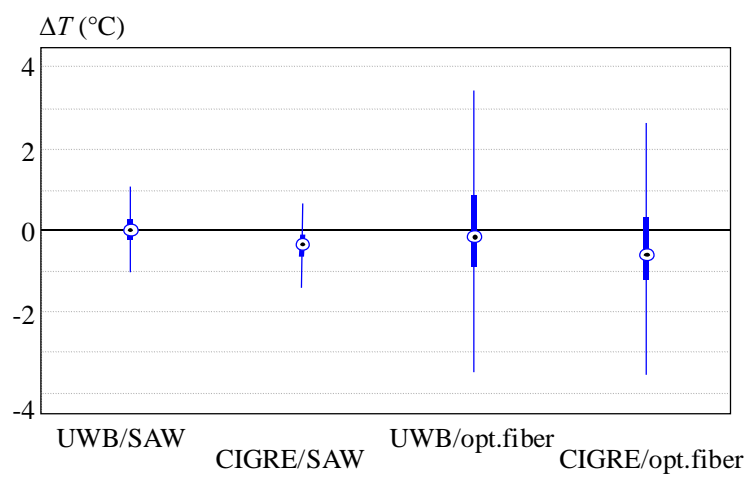

Fig. 6. Evaluation of temperature difference between modeled and measured values for surface and inner sensors; University of West Bohemia (UWB) and CIGRE models

3) Temperature ampacity - determined by ambient temperature and sun radiation intensity, both measured or predicted, at constant wind parameters; proper for short-term (hours, days) ampacity prediction,

4) Dynamic ampacity - instantaneous reserve for conductor overloading given by time constant and the temperature difference between immediate and maximum value,

5) Weather ampacity - instant ampacity of a line affected by all of the weather factors.

\subsection{Standardized ampacity}

Present-day ampacity determination is based on a worst-case weather conditions scenario. On one hand its indisputable advantage lies in a lifetime operation security, but on the other hand the conductor current carrying capacity stays most of the time underrated.

The Czech national standard [22] presents following values as standard conditions: maximum conductor temperature $T_{c}=80^{\circ} \mathrm{C}$, ambient temperature $T_{a m b}=$ $35{ }^{\circ} \mathrm{C}$, solar radiation intensity $I_{s}=1000 \mathrm{~W} / \mathrm{m}^{2}$, and wind speed $v=0.5 \mathrm{~m} / \mathrm{s}$ inclined to a conductor at angle $\phi=45^{\circ}$. The surveyed three bundle conductor is rated $2000 \mathrm{~A}$ accordingly.

A statistics considering measured weather conditions was made to evaluate present standardized ampacity. Table 1 shows, how many times the conductor temperature would have risen above $80{ }^{\circ} \mathrm{C}$ at nominal loading and how long it would have taken in total. It is obvious that defined nominal current is reasonable, because the lowering of actual ampacity below the static limit occurs annually in the order of hours.

\subsection{Statistical ampacity}

The application of the statistical ampacity can be especially helpful in planning of a transmission grid operation outside reliable weather forecast period. Compared to the temperature ampacity, this method can determine ampacity range for any desired time interval.

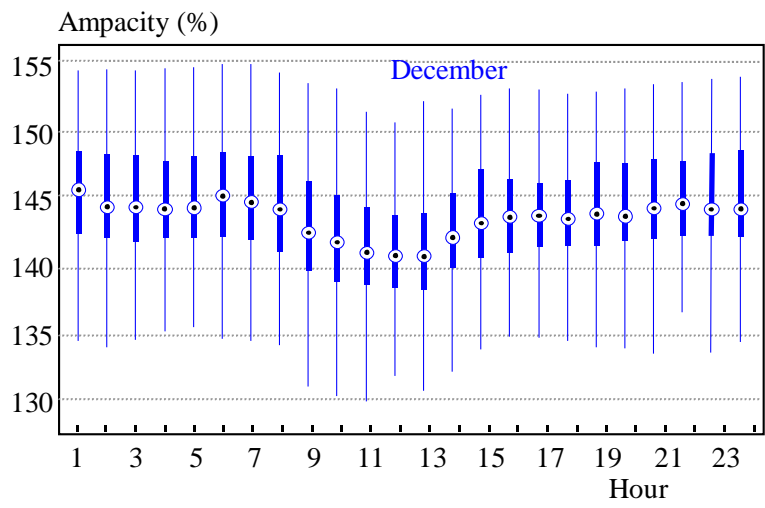

Fig. 7. Ampacity during December sorted by hour

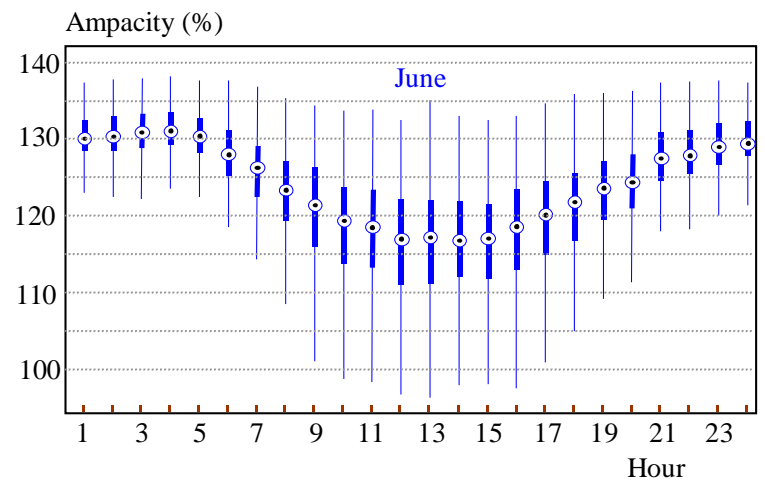

Fig. 8. Typical ampacity range affected by summer sun radiation 
Table 1. Ampacity below static limit according to measured weather conditions

\begin{tabular}{cccc}
\hline Year & $\begin{array}{c}\text { Times } \\
\text { below limit }\end{array}$ & Total time & $\begin{array}{c}\text { Risk percentage } \\
\text { per year }\end{array}$ \\
\hline 2010 & 121 & $11 \mathrm{~h} 39 \mathrm{~m}$ & $0.133 \%$ \\
2011 & 84 & $3 \mathrm{~h} 10 \mathrm{~m}$ & $0.036 \%$ \\
2012 & 126 & $3 \mathrm{~h} 30 \mathrm{~m}$ & $0.040 \%$ \\
\hline
\end{tabular}

For instance Fig. 7 shows ampacity range made of measured ambient temperature and sun radiation intensity. The data were selected from measurements during December 2010, 2011 and 2012 and sorted by hour. The information for an operator says, that it is highly probable, that the ampacity at noon in December would not fall below $130 \%$ of nominal level. The same way of data selection for June is shown in Fig. 8. The trend is more dramatic because of higher sun radiation intensity. Other possible combinations can lead to for instance winter and summer ampacity regime or day and night regime according to a present month.

\subsection{Temperature ampacity}

Prediction of ampacity always represents a difficult task when an operator needs to compile a next-day schedule. It is given by the variety of wind conditions and cloudiness along transmission lines. The proposed method is based on a prediction of temperature, while calculating or measuring the maximum solar radiation intensity and setting wind speed and angle at a certain level giving steadier values to an operator. It also suits perfectly for a next-day operation plan in an interval of 36 hours.

The only question is how to set wind speed and angle. Presumption of the worst case, when a conductor is cooled just by natural convection, results in highly conservative approach. Although it means zero risk of conductor temperature exceeding, in extreme hot weather the dynamic limit may drop below the stationary value. Another option is to set minimal expected wind conditions on a certain level, ie $v=0.5 \mathrm{~m} / \mathrm{s}$ and $\phi=45^{\circ}$. In Fig. 9 the ampacity gain is about $15-20 \%$ for the "low risk" than the worst case scenario of zero wind conditions presented by the "zero risk" curve. The oscillations are caused by measuring the actual sun radiation.

Risk analyses indicated that conductor temperature for the "low risk" setting would be exceeded in 8-16\% of examined data time. Historical extremes of both approaches are compared in Fig. 10. This method is mainly usable when weather monitoring stations are not available. It can be easily connected with temperature forecast because of the smooth trend of output data. Also the minimal expected wind conditions can be derived from weather forecast.

\subsection{Dynamic ampacity}

The third proposed method derives benefit from the ability of a conductor to accumulate heat and complements other methods in order to make the most of DLR technology. Usually conductor time constant is about 15 minutes. Thus it allows temporary overloading in dependence on previous temperature.

Maximum overcurrent can be easily defined as shown in Fig. 11. Contrary to [23] curves create continuous limit representing maximum conductor temperature. For instance, if previous temperature matches $75 \%$ of nominal current and an operator needs to load the line on $150 \%$, maximum time available for this operation is 5 minutes. As seen in the figure, the applicability of this method is limited because of the response time of operators, which is at best 20 minutes.

\subsection{Weather ampacity}

If a measurement system of ambient conditions is available to an operator, line ampacity can be fully determined. Its main advantage lies in the possibility of the static ampacity value multiplication but at the cost of rapid oscillation caused by changing wind conditions along the observed line. Comparison between weather and temperature ampacity is shown in Fig. 12. This kind of DLR model can be also integrated with switchgear and transformers ampacity as shown in [24] in order to maximize the benefit of the technology.

Although measurement can ensure validity of present ampacity value, it is rather improper for ampacity forecast because of its deterministic nature. A Bayesian approach $[25,26]$ can provide information about short-term ampacity prediction and, in particular, it can estimate the actual risk of exceeding the ampacity value. In this way grid operators will be able to react successfully and utilize the whole ampacity range in a safe way.

The only bottleneck for all of the ampacity determination methods could be represented by specific local conditions. The line vicinity ( $i e$ forest, buildings) can, for instance, significantly change air flow at a single place. Thus the one anomaly could affect whole line. A history of extreme ampacity values for each month is depicted in Fig. 13. It shows the overall ampacity range, the bottom limit is rather stable, while the upper one is strongly dependent on local conditions.

On one hand modeling of conductor temperature using deterministic methods, while neglecting factors such as evaporative cooling or icing as well as the effect of cloudiness, produces common error of $\pm 1{ }^{\circ} \mathrm{C}$ for surface temperature measurement and $\pm 3{ }^{\circ} \mathrm{C}$ for inner optical fiber sensor. On the other hand all of these factors should cause conductor temperature drop thus they do not mean any threat to the temperature limit exceeding.

\section{DISCUSSION}

Based on the modeled and measured conductor temperature deviation, a method for ampacity determination solely from ambient temperature measurement or prediction was introduced. Its main advantage lies in reduction of needed sensors for acquiring weather data along a line, 


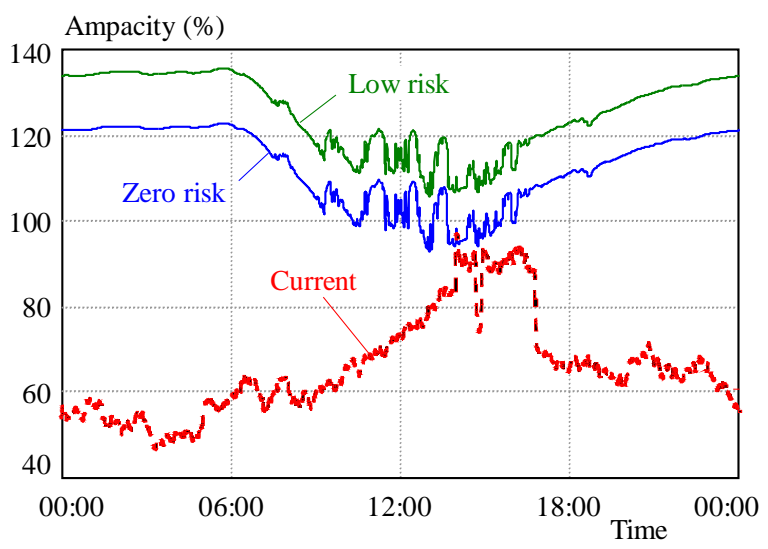

Fig. 9. Temperature ampacity compared to peak current for different wind conditions

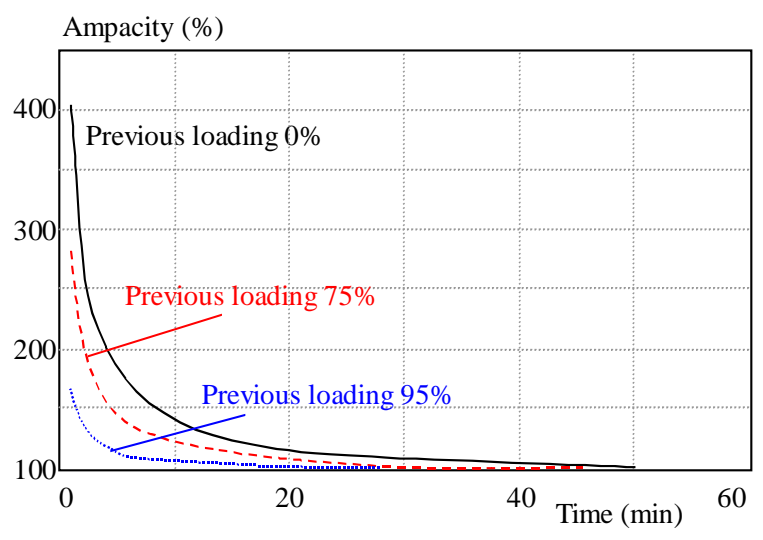

Fig. 11. Relation between overcurrent and its maximum time duration based on previous loading

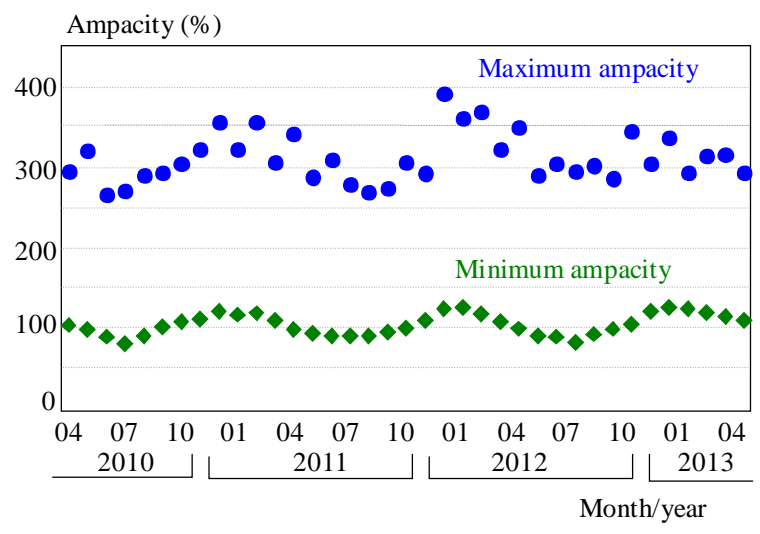

Fig. 13. Calculated trend of minimum and maximum line ampacity for each month during measurements

while it offers a decent ampacity limit increase in the order of tens of percent of nominal current. Also a natural stability and predictability of ambient temperature give the operators a possibility to prepare a reliable plan of operation for a particular line. But all of the mentioned benefits are knocked down by reduced ampacity gain and a likelihood that the dynamic ampacity could drop below the present value.

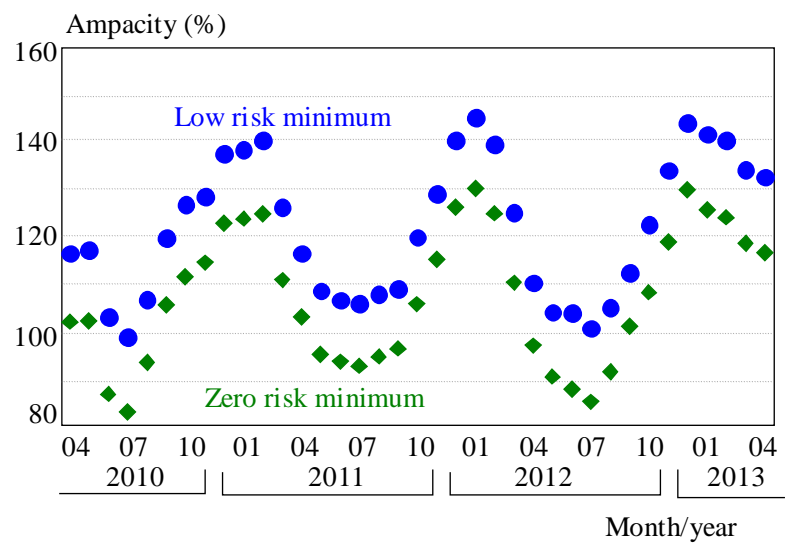

Fig. 10. Calculated minimum temperature ampacity for each month at different wind conditions

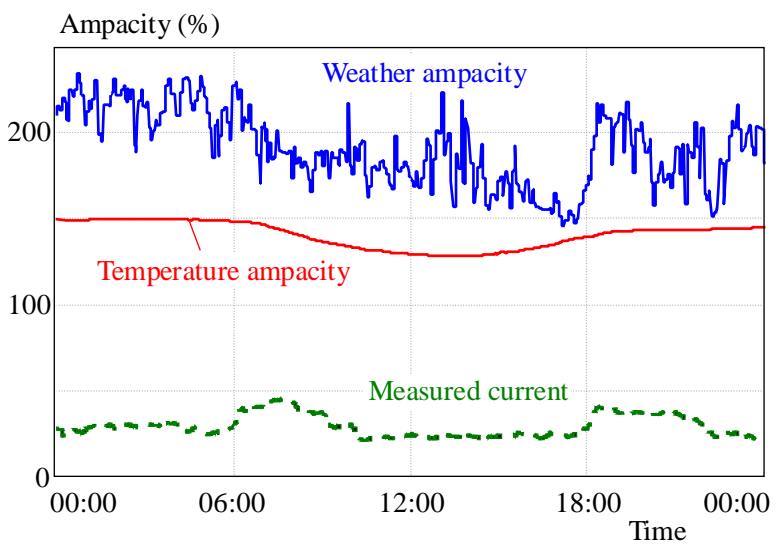

Fig. 12. The difference between ampacity determination approaches

\section{CONCLUSION}

Introducing the DLR technology into operation raised a lot of questions on efficiency and safety. The developed deterministic thermal model can be further complemented with a stochastic approach. Although it is possible to dynamically raise ampacity level, the risk assessment of exceeding the highest permitted temperature or maximum sag is rather limited.

Minimizing the number of weather or temperature sensors represented another challenge. A new method was proposed, which is able to utilize conductor current carrying capacity while keeping relatively stable prediction curve. Despite its lower ampacity gain, an easy integration with ambient temperature prediction along the whole overhead line can provide a reliable and cost effective solution. Future effort in this area will probably lead to the development of probabilistic methods to deal with model errors.

\section{Acknowledgment}

This research has been supported by the European Regional Development Fund and the Ministry of Education, Youth and Sports of the Czech Republic under 
the Regional Innovation Centre for Electrical Engineering (RICE), project No. CZ.1.05/2.1.00/03.0094, and by the student science project SGS-2012-047. Authors thank to ČEPS, a.s. and especially to Mr. Jiří Velek for helpful cooperation with ongoing research.

\section{REFERENCES}

[1] CIGRE Joint Working Group B2.C1: Increasing Capacity of Overhead Transmission Lines: Needs and Solutions, CIGRE, 2010.

[2] FERNANDEZ, E.-ALBIZU, I.-BEDIALAUnETA, M. T.MAZON, A. J.-LEITE, P. T.: Dynamic Line Rating Systems for Wind Power Integration, Power Engineering Society Conference and Exposition in Africa (PowerAfrica), IEEE, 2012, pp. 1-7.

[3] KLEIN, K. M.-SPRINGER, P. L.-BLACK, W. Z.: RealTime Ampacity and Ground Clearance Software for Integration into Smart Grid Technology, Power and Energy Society General Meeting, IEEE, 2011, pp. 1-11.

[4] SCHMALE, M.-PUfFER, R.-HEIDEMANN, M. : Dynamic Ampacity Rating of Conductor Bars in Highly Loaded Substations, CIRED 2013: 22nd International Conference and Exhibition on Electricity Distribution, 2013, pp. 1-4.

[5] FU, J.-ABDELKADER, S.-MORROW, D. J.-FOX, B. : Partial Least Squares Modelling for Dynamic Overhead Line Ratings, PowerTech, 2011 IEEE Trondheim, 2011, pp. 1-6.

[6] FU, J.-MORROW, D. J.-ABDELKADER, S. M. : Modelling and Prediction Techniques for Dynamic Overhead Line Rating, Power and Energy Society General Meeting, 2012 IEEE, 2012, pp. $1-7$.

[7] ARNOLD, P.-KMENT, A.-PÍPA, M.-JANÍČEK, F.: Onsite Partial Discharges Measurement of XLPE Cables, Transactions On Electrical Engineering 123, (2012), 107.

[8] STEPHEN, R.-DOUGLAS, D.-MIROSEVIC, G.-ARGASINSKA, H.-BAKIC, K.-HOFFMAN, S.-IGLESIAS, J.JAKL, F.-KATOH, J.-KIKUTA, T. and others: Thermal Behaviour of Overhead Conductors, Cigré, 2002.

[9] IEEE Standard for Calculating the Current-Temperature of Bare Overhead Conductors, IEEE Std 738-2006 (Revision of IEEE Std 738-1993), IEEE Power Engineering Society, 2007, pp. c1-59.

[10] TLUSTÝ, J.: Monitorování, řízení a chránění elektrizačních soustav, České vysoké učení technické v Praze, 2011.

[11] PYTLAK, P.-MUSILEK, P.-LOZOWSKI, E., : Precipitation-Based Conductor Cooling Model for Dynamic Thermal Rating Systems, Electrical Power Energy Conference (EPEC), 2009 IEEE, 2009, pp. 1-7.

[12] CIGRE Working Group B2.12 and International Council on Large Electric Systems: Guide for Selection of Weather Parameters for Bare Overhead Conductor Ratings, CIGRE, 2006.

[13] LE, T. L.-NEGNEVITSKY, M.-PIEKUTOWSKI, M. : Expert System Application for the Loading Capability Assessment of Transmission Lines, Power Systems, IEEE Transactions on 10 No. 4 (1995), 1805-1812.

[14] ROGLER, R. D.: Infrarotdiagnose an Verbindungen der energetischen Elektrotechnik, Fortschrittberichte VDI, ser. 21, VDI Verlag, 1999.

[15] VOSTRACKY, Z.-HALLER, R.: Impact of Radiation on the Thermal Behaviour of an Overhead Line Rope, 12th International Scientific Conference Electric Power Engineering, VSB Technical University of Ostrava, 2011, pp. 615-618.

[16] SNAJDR, J.-VOSTRACKY, Z.-SEDLACEK, J.: Evaluation of Theoretical Results of Overhead Line Ampacity Model, Proceedings of the 7th International Scientific Symposium on
Electrical Power Engineering, Technical University of Košice, 2013, pp. 152-154.

17] GOGA, V.-PAULECH, J.-VÁRY, M. : Cooling of Electrical $\mathrm{Cu}$ Conductor with PVC Insulation - Analytical, Numerical and Fluid Flow Solution, J. Electrical Engineering 64 No. 2 (2013), 92-99.

[18] VÁRY, M.-GOGA, V.-PAULECH, J.: Experimental, Analytical and Computational Approaches to Bare Electric Wire Loading Characteristics, Electrotechnica, Electronica, Automatica 60 No. 3 (2012), 14-21.

[19] VDI : VDI Heat Atlas, Springer, 2010.

[20] Nktcables: VALCAP Grid Monitoring and Rating for High Voltage Cables and Overhead Lines, www.nktcables.com.

[21] RIBE: RITHERM - Temperature Monitoring and Load Optimization on Overhead Transmission Lines, 2014.01.06, www.ribe.de.

[22] CNI, : Overhead Electrical Lines Exceeding AC $45 \mathrm{kV}$, Part 3: Set of National Normative Aspects, Section 19: National Normative Aspects for the Czech Republic, CSN EN 50341319 , Česky normalizační institut, 2003.11.25.

[23] MUSAVI, M.-CHAMBERLAIN, D.-LI, Q. : Overhead Conductor Dynamic Thermal Rating Measurement and Prediction, Smart Measurements for Future Grids (SMFG), 2011 IEEE International Conference on, 2011, pp. 135-138.

24] KIM, S. D.-MORCOS, M. M.: An Application of Dynamic Thermal Line Rating Control System to Up-Rate the Ampacity of Overhead Transmission Lines, Power Delivery, IEEE Transactions on 28 No. 2 (2013), 1231-1232.

[25] ZHANG, J.-PU, J.-McCALLEY, J. D.-STERN, H.-GALLUS, W. A., Jr.: A Bayesian Approach for Short-Term Transmission Line Thermal Overload Risk Assessment, Power Delivery, IEEE Transactions on 17 No. 3 (2002), 770-778.

[26] WANG, K.-SHENG, G.-JIANG, X.: Risk Assessment of Transmission Dynamic Line Rating based on Monte Carlo, IEEE Power Engineering and Automation Conference (PEAM), vol. 2, 2011, pp. 398-402.

Received 8 January 2014

Jaroslav Šnajdr born in 1986, received the Engineer degree (MSc) in Electrical Power Engineering from the Faculty of Electrical Engineering of the University of West Bohemia, Pilsen in 2011. He is currently continuing his studies at the same department as a PhD student. His dissertation research is focused on dynamic overhead line rating. Other activities include thermal management of switchgear, both outdoor and gas insulated, and research of dynamic rating of power cables. He is a member of the Regional Innovation Centre of Electrical Engineering.

Jan Sedláček born in 1972, received MSc and $\mathrm{PhD}$ degrees at the Faculty of Electrical Engineering of the University of West Bohemia. Since 2001 he works at the university in the New Technologies - Research Centre and Faculty of Electrical Engineering. He currently works in the field of electricity, numerical simulations, CFD and as a lecturer.

Zdeněk Vostracký born in 1941, studied at the Institute of Technology in Pilsen, defended Doctor of Science at the Technical University in Prague and received an honorary doctorate in London at Brunel University. He worked in the company ŠKODA Plzeň in 1989-1992 as the Chairman of the Board and in 1998-2004 as the Rector of the University of West Bohemia in Pilsen. He currently works in the field of electricity, electrical appliances and plasma physics and as a lecturer at the Faculty of Electrical Engineering of the University of West Bohemia in Pilsen. He is a member of the Regional Innovation Centre of Electrical Engineering. 